\title{
Components of the metabolic syndrome in early childhood in very-low-birth-weight infants and term small and appropriate for gestational age infants
}

\author{
Miranda de Jong ${ }^{1}$, Anneke Cranendonk ${ }^{2}$ and Mirjam M. van Weissenbruch ${ }^{2}$
}

BACKGROUND: Term small-for-gestational-age (SGA) and preterm born infants have an increased prevalence of metabolic syndrome components already in childhood. Our recent study in 2-y-old very-low-birth-weight (VLBW) infants was limited by the absence of a control group of term born children. We compared the metabolic syndrome components in early childhood in VLBW and term SGA infants to term appropriate for gestational age (AGA) infants.

METHODS: We included 38 VLBW children and 82 term born children (64 AGA/18 SGA). HDL cholesterol, triglycerides, glucose, and insulin were measured in blood samples taken at $1 \mathrm{y}$ (term children) and 2 y (all children) of (corrected) age.

RESULTS: At 2 y corrected age, VLBW children have lower $\mathrm{BMI}$ and higher glucose level compared to AGA children. SGA children have lower BMI at 1 and 2 y of age and a high prevalence of high triglyceride levels at $1 \mathrm{y}$ of age compared to AGA children. Total body fat is a significant determinant of HDL cholesterol and triglycerides and birth weight is a significant determinant of glucose at 2 y corrected age.

CONCLUSION: In early childhood, VLBW and term SGA children already have a high prevalence of some metabolic syndrome components compared to term AGA children.

$\mathbf{T}$ he metabolic syndrome is a combination of abnormalities in metabolic parameters, body size and blood pressure and is associated with an increased risk of type 2 diabetes and cardiovascular disease. Besides life style and obesity, fetal and early postnatal growth are determinants of the metabolic syndrome. This is based on the studies of Barker et al. (1), who first indicated the importance of fetal growth for development of the metabolic syndrome in adulthood and showed an increasing prevalence with decreasing birth weight. Not only term smallfor-gestational-age (SGA) born infants, but also preterm born infants have an increased prevalence of several components of the metabolic syndrome, already in childhood (2-9). The relation between metabolic syndrome components in childhood and fetal growth was studied by Jaddoe et al. (10); they showed that first trimester fetal growth restriction is associated with an adverse cardiovascular risk profile at $6 \mathrm{y}$ of age.
We recently showed that at the corrected age of 2 y verylow-birth-weight (VLBW) infants already have a high prevalence of components of the metabolic syndrome (11). In that study $63 \%$ had raised blood pressure (systolic and/or diastolic $\geq 90$ th percentile for age, sex, and height), 32\% low HDL cholesterol $(\leq 1.03 \mathrm{mmol} / \mathrm{l})$ and $30 \%$ high triglycerides $(\geq 0.98$ $\mathrm{mmol} / \mathrm{l}$ ); none of the children had high BMI (BMI standard deviation scores (SDS) $>2$ for age and sex) or high glucose $(\geq 5.6 \mathrm{mmol} / \mathrm{l})$. This study was limited by the absence of a control group of term born children and consequently the cut-off values for several metabolic syndrome components were based on studies in other populations (12-15).

The aim of the present study was to compare the components of the metabolic syndrome in VLBW infants at the corrected age of $2 \mathrm{y}$ with those in 2-y-old term appropriate for gestational age (AGA) born children. The second aim was to compare the components of the metabolic syndrome in term SGA infants with those in term AGA infants at 1 and $2 \mathrm{y}$ of age.

\section{RESULTS}

In our unit, 47 VLBW infants participated in the Neonatal Insulin Replacement Therapy in Europe (NIRTURE) trial. Five infants died and two children were lost to follow-up. At the corrected age of $2 y, 40$ children visited our outpatient clinic. Two children were excluded because the parents refused blood sampling, 38 VLBW children were included in the present study. Three $(8 \%)$ of these VLBW children were SGA. Seventeen infants ( 9 male/8 female) were assigned to the early-insulin group and 21 infants (10 male/11 female) received standard neonatal care. We included all VLBW children as one group in the analyses; comparison between the early-insulin treated group and standard care group has been described earlier (11).

Ninety term born infants were included in the follow-up part of the Trophoblast study: 72 AGA and 18 SGA. Eight children were lost to follow-up after the first visit at 3 mo of age; 82 term born children (64 AGA and 18 SGA) were included in the present study. Of these 82 children, 6 AGA children and 1 SGA child were lost to follow-up at $2 \mathrm{y}$ of age.

Table 1 shows the gestational age and birth weight (SDS) of the VLBW children and term AGA and SGA children. For the 
Table 1. Characteristics of the VLBW and term (AGA and SGA) children at birth and term age

\begin{tabular}{lccc}
\hline & $\begin{array}{c}\text { VLBW } \\
(n=38) \\
(19 \mathrm{M} / 19 \mathrm{~F})\end{array}$ & $\begin{array}{c}\text { Term AGA } \\
(n=64) \\
(35 \mathrm{M} / 29 \mathrm{~F})\end{array}$ & $\begin{array}{c}\text { Term SGA } \\
(n=18) \\
(8 \mathrm{M} / 10 \mathrm{~F})\end{array}$ \\
\hline At birth & & & \\
Gestational age (wk) & $27.9 \pm 1.3^{*}$ & $39.3 \pm 1.2$ & $38.9 \pm 1.2$ \\
Weight (g) & $1,059 \pm 226^{*}$ & $3,529 \pm 393$ & $2,463 \pm 251^{+}$ \\
Weight SDS & $-0.03 \pm 0.8$ & $0.3 \pm 0.7$ & $-2.1 \pm 0.6^{+}$ \\
At term age & & & \\
Weight (g) & $3,162 \pm 558$ & & \\
Weight SDS & $-1.2 \pm 1.3$ & & \\
\hline
\end{tabular}

All data are expressed as mean \pm SD. Standard deviation scores (SDS) at birth according to Niklasson (28) and at term age according to dutch references (23).

AGA, appropriate for gestational age; SGA, small-for-gestational-age; VLBW, very-lowbirth weight.

VLBW infants are compared to term AGA infants. Marked data are significantly different: ${ }^{*} P<0.01$. Term SGA infants are compared to term AGA infants. Marked data are significantly different: ${ }^{+} P<0.01$.

VLBW children, the weight (SDS) at term age is also shown. Their weight (SDS) at term age is significantly lower than the birth weight (SDS) of term AGA children $(P<0.001)$ and significantly higher than the birth weight (SDS) of the term SGA children $(P<0.001)$.

\section{Anthropometry}

Table 2 shows the weight (SDS), length (SDS), and total body fat at $3 \mathrm{mo}, 1 \mathrm{y}$, and $2 \mathrm{y}$ of (corrected) age for the VLBW children, term AGA and term SGA children. The data show that during the first 2 y of life VLBW children and term SGA children stay lighter than term AGA children. In the first year of life they are also shorter, but at $2 \mathrm{y}$ of (corrected) age the length of VLBW and term SGA children does not differ significantly from term AGA children. In contrast to term SGA children, VLBW children have lower body fat percentage compared to term AGA children at all ages.

We compared the growth of VLBW children and term SGA children with the growth of term AGA children by comparing the change in weight (SDS) and length (SDS) between 0 and 3 mo, 3 mo and $1 \mathrm{y}, 1$ and $2 \mathrm{y}$, and 0 mo and $1 \mathrm{y} / 2 \mathrm{y}$ of (corrected) age. When comparing VLBW children to term AGA children, most differences were found between 3 mo and 1 y of corrected age. In VLBW children, the increment in length (SDS) was more than in term AGA children, resulting in the disappearance of the difference in length between VLBW and term AGA children with increasing age (Table 2). The increment in weight in this period was less in VLBW children compared to term AGA children. In term SGA children, the increment in weight SDS between birth and 3 mo, birth and $1 \mathrm{y}$, and birth and $2 \mathrm{y}$ was significantly greater than in term AGA children.

\section{Metabolic Syndrome Components}

Table 3 shows the components of the metabolic syndrome in term (AGA and SGA) children at 1 and $2 y$ of age and in the VLBW children at $2 \mathrm{y}$ of corrected age. At $2 \mathrm{y}$ corrected age
Table 2. Weight, length, and total body fat of the VLBW and term (AGA and SGA) children at $3 \mathrm{mo}, 1 \mathrm{y}$, and $2 \mathrm{y}$ of (corrected) age

\begin{tabular}{|c|c|c|c|}
\hline & $\begin{array}{c}\operatorname{VLBW}(n=38) \\
(19 \mathrm{M} / 19 \mathrm{~F})\end{array}$ & $\begin{array}{c}\text { Term AGA }(n=64) \\
(35 \mathrm{M} / 29 \mathrm{~F})\end{array}$ & $\begin{array}{c}\text { Term SGA }(n=18) \\
(8 M / 10 F)\end{array}$ \\
\hline \multicolumn{4}{|c|}{ At 3 mo (corrected) age } \\
\hline Weight (kg) & $5.6 \pm 0.9^{*}$ & $6.2 \pm 0.6$ & $5.4 \pm 0.7^{\dagger}$ \\
\hline Weight SDS & $-0.5 \pm 1.3^{*}$ & $0.5 \pm 0.7$ & $-0.5 \pm 0.8^{\dagger}$ \\
\hline Length $(\mathrm{cm})$ & $58.2 \pm 2.7^{*}$ & $61.4 \pm 2.0$ & $58.7 \pm 3.2^{+}$ \\
\hline Length SDS & $-1.1 \pm 1.1^{*}$ & $0.4 \pm 0.7$ & $-0.5 \pm 1.1^{\dagger}$ \\
\hline Total body fat (kg) & $1.0 \pm 0.5^{*}$ & $1.3 \pm 0.3$ & $1.0 \pm 0.3^{+}$ \\
\hline TBF/weight & $0.18 \pm 0.06^{* *}$ & $0.20 \pm 0.04$ & $0.19 \pm 0.05$ \\
\hline \multicolumn{4}{|c|}{ At 1 y (corrected) age } \\
\hline Weight (kg) & $9.1 \pm 1.1^{*}$ & $10.1 \pm 1.0$ & $9.2 \pm 1.0^{\dagger}$ \\
\hline Weight SDS & $-0.9 \pm 1.0^{*}$ & $0.1 \pm 0.8$ & $-0.7 \pm 0.9^{\dagger}$ \\
\hline Length $(\mathrm{cm})$ & $74.5 \pm 2.8^{*}$ & $76.5 \pm 2.4$ & $74.5 \pm 3.3^{\ddagger}$ \\
\hline Length SDS & $-0.6 \pm 1.0^{*}$ & $0.1 \pm 0.8$ & $-0.5 \pm 1.3^{\ddagger}$ \\
\hline Total body fat (kg) & $1.7 \pm 0.6^{*}$ & $2.3 \pm 0.7$ & $1.9 \pm 0.6^{\ddagger}$ \\
\hline TBF/weight & $0.18 \pm 0.06^{*}$ & $0.22 \pm 0.05$ & $0.21 \pm 0.05$ \\
\hline \multicolumn{4}{|c|}{ At 2 y (corrected) age } \\
\hline Weight (kg) & $11.6 \pm 1.2^{*}$ & $13.0 \pm 1.5$ & $11.9 \pm 1.2^{+}$ \\
\hline Weight SDS & $-0.9 \pm 0.9^{*}$ & $0.1 \pm 0.9$ & $-0.6 \pm 0.8^{\dagger}$ \\
\hline Length (cm) & $86.2 \pm 3.6$ & $87.7 \pm 3.3$ & $86.1 \pm 4.7$ \\
\hline Length SDS & $-0.6 \pm 1.1$ & $-0.3 \pm 0.9$ & $-0.6 \pm 1.4$ \\
\hline Total body fat $(\mathrm{kg})$ & $1.8 \pm 0.6^{*}$ & $2.6 \pm 1.0$ & $2.2 \pm 0.6^{\ddagger}$ \\
\hline TBF/weight & $0.16 \pm 0.05^{*}$ & $0.20 \pm 0.06$ & $0.18 \pm 0.04$ \\
\hline
\end{tabular}

All data are expressed as mean \pm SD. Standard deviation scores (SDS) according to dutch references (23).

AGA, appropriate for gestational age; SGA, small-for-gestational-age; TBF, total body fat; VLBW, very-low-birth weight.

VLBW children are compared to term AGA children. Marked data are significantly different: ${ }^{*} P<0.01 ;{ }^{*} P<0.05$. Term SGA children are compared to term AGA children. Marked data are significantly different: ${ }^{\dagger} P<0.01 ; \neq P<0.05$.

VLBW children have lower BMI (SDS) but higher glucose levels than term AGA children. At 1 and 2 y of age term SGA children have lower BMI (SDS) than term AGA children.

In Table 4, we used the 75th and 90th percentile values of the metabolic syndrome components (25th and 10th percentile for HDL cholesterol) of our control group of term AGA children as cut-off values for the metabolic syndrome components in VLBW and term SGA children. The table shows the percentage of VLBW children and term SGA children with a value at or above the 75th and 90th percentile (for HDL cholesterol, at or below the 25th and 10th percentile). At $1 \mathrm{y}$ of age, the prevalence of triglycerides $\geq$ p75 was significantly higher in term SGA children compared to AGA children. At 2 y of age, VLBW children had a higher prevalence of glucose $\geq \mathrm{p} 75$ and glucose $\geq$ p90 than term AGA children.

\section{Correlation and Multiple Regression Analysis}

In the term born children (AGA and SGA), HDL cholesterol at $1 \mathrm{y}$ of age was significantly correlated to birth weight $(r=$ $0.26 ; P=0.025$ ), but not to body size and composition (weight, length, BMI, total body fat) at $1 \mathrm{y}$. Glucose level at $1 \mathrm{y}$ of age 
Table 3. Components of the metabolic syndrome, insulin, and HOMA in VLBW and term (AGA and SGA) children at 1 and $2 \mathrm{y}$ of (corrected) age

\begin{tabular}{lccc}
\hline At 1 y (corrected) age & & $\begin{array}{c}\text { Term AGA } \\
(n=64)\end{array}$ & $\begin{array}{c}\text { Term SGA } \\
(n=18)\end{array}$ \\
\hline BMI (kg/m²) & $17.2 \pm 1.3$ & $16.5 \pm 1.3^{\ddagger}$ \\
BMI SDS & & $0.1 \pm 0.9$ & $-0.5 \pm 1.0^{\ddagger}$ \\
Glucose (mmol/l) & $3.9 \pm 0.8$ & $4.2 \pm 0.4$ \\
Total cholesterol (mmol/l) & & $3.9 \pm 0.8$ & $3.5 \pm 0.7$ \\
HDL cholesterol (mmol/l) & & $1.0 \pm 0.3$ & $0.9 \pm 0.3$ \\
Triglycerides (mmol/l) & & $1.4 \pm 0.7$ & $1.8 \pm 1.0$ \\
Insulin (pmol/l) & & $15.7(1.0-179.4)$ & $19.9(1.0-86.5)$ \\
HOMA & & $0.4(0.01-5.2)$ & $0.5(0.02-2.7)$ \\
\hline & & Term AGA & Term SGA \\
At 2 y (corrected) age & $(n=38)$ & $(n=58)$ & $(n=17)$ \\
\hline BMI (kg/m²) & $15.6 \pm 1.5^{*}$ & $16.9 \pm 1.1$ & $16.0 \pm 0.8^{\dagger}$ \\
BMI SDS & $-0.6 \pm 1.2^{*}$ & $0.5 \pm 0.8$ & $-0.1 \pm 0.6^{\dagger}$ \\
Glucose (mmol/l) & $4.5 \pm 0.5^{*}$ & $4.0 \pm 0.7$ & $4.0 \pm 0.5$ \\
Total cholesterol (mmol/l) & $3.9 \pm 0.8$ & $4.1 \pm 0.7$ & $3.9 \pm 0.7$ \\
HDL cholesterol (mmol/l) & $1.2 \pm 0.3$ & $1.1 \pm 0.3$ & $1.0 \pm 0.3$ \\
Triglycerides (mmol/l) & $1.0 \pm 0.7$ & $1.2 \pm 0.6$ & $1.2 \pm 0.5$ \\
Insulin (pmol/l) & 21.0 & 17.9 & 20.4 \\
HOMA & $(1.0-190.9)$ & $(1.0-181.1)$ & $(1.0-95.2)$ \\
& 0.6 & 0.5 & 0.5 \\
\hline Data & $(0.02-6.5)$ & $(0.01-5.6)$ & $(0.02-2.9)$ \\
\hline
\end{tabular}

Data are expressed as mean \pm SD for normally distributed values and as median (range) for not normally distributed values.

VLBW children are compared to term AGA children. Marked data are significantly different: ${ }^{*} P<0.01$. Term SGA children are compared to term AGA children. Marked data are significantly different: ${ }^{+} P<0.01 ; \neq P<0.05$

was significantly correlated to weight $(r=0.54 ; P=0.03)$ only in SGA children, but not in AGA children. Triglycerides at 1 $\mathrm{y}$ of age were not correlated to birth weight or body size and composition at $1 \mathrm{y}$. In multiple regression analysis, only birth weight as predictor of HDL cholesterol at $1 \mathrm{y}$ was significant.

In the total group of children (term and VLBW), HDL cholesterol and triglycerides at $2 \mathrm{y}$ of (corrected) age were significantly correlated to total body fat $(r=-0.21 ; P=0.033$ and $r=$ $0.20 ; P=0.038$ respectively) and to total body fat/weight $(r=$ $-0.22 ; P=0.021$ and $r=0.23 ; P=0.019$ respectively). Glucose at $2 \mathrm{y}$ of (corrected) age was significantly correlated to birth weight $(r=-0.37 ; P<0.001)$. Only in term born children, glucose at $2 \mathrm{y}$ of age was significantly correlated to total body fat $(r=0.29$; $P=0.016)$, weight $(r=0.32 ; P=0.005)$, and length $(r=0.30$; $P=0.009$ ) at 2 y of age. The strongest correlation of glucose to weight and length at $2 \mathrm{y}$ was found in the SGA children $(r=$ $0.69 ; P=0.002$ and $r=0.51 ; P=0.036$ respectively). Multiple regression analysis showed that total body fat is a significant determinant of HDL cholesterol and triglycerides and birth weight is a significant predictor of glucose at $2 \mathrm{y}$ corrected age.

\section{Insulin and HOMA}

The results of the insulin measurements and homeostatic model assessment (HOMA) calculations are also shown in Table 3.
Table 4. Classification of the components of the metabolic syndrome in VLBW and term SGA children based on the percentile values of term AGA children

\begin{tabular}{|c|c|c|c|c|c|}
\hline $\begin{array}{l}\text { At } 1 \text { y } \\
\text { (corrected) age }\end{array}$ & \multicolumn{2}{|c|}{ Term AGA } & \multicolumn{2}{|c|}{ Term SGA } & \\
\hline \multirow[t]{2}{*}{ BMI } & p75 & 18.0 & $\geq$ p75 & $2 / 18(11 \%)$ & \\
\hline & p90 & 18.8 & $\geq \mathrm{p} 90$ & $0 / 18$ & \\
\hline \multirow{2}{*}{$\begin{array}{l}\text { Glucose } \\
(\mathrm{mmol} / \mathrm{l})\end{array}$} & p75 & 4.5 & $\geq$ p75 & $3 / 16(19 \%)$ & \\
\hline & p90 & 4.8 & $\geq \mathrm{p} 90$ & $2 / 16(13 \%)$ & \\
\hline \multirow{2}{*}{$\begin{array}{l}\text { HDL cholesterol } \\
(\mathrm{mmol} / \mathrm{l})\end{array}$} & p25 & 0.8 & $\leq \mathrm{p} 25$ & $5 / 16(31 \%)$ & \\
\hline & p10 & 0.7 & $\leq \mathrm{p} 10$ & 4/16 (25\%) & \\
\hline \multirow{2}{*}{$\begin{array}{l}\text { Triglycerides } \\
\text { (mmol/l) }\end{array}$} & p75 & 1.7 & $\geq$ p75 & $9 / 16(56 \%)^{\mathrm{a}}$ & \\
\hline & p90 & 2.4 & $\geq \mathrm{p} 90$ & $2 / 16(13 \%)$ & \\
\hline $\begin{array}{l}\text { At } 2 y \\
\text { (corrected) age }\end{array}$ & \multicolumn{2}{|c|}{ Term AGA } & \multicolumn{2}{|r|}{ VLBW } & Term SGA \\
\hline \multirow[t]{2}{*}{ BMI } & p75 & 17.5 & $\geq$ p75 & 4/38 (11\%) & $\geq p 75 \quad 0 / 17$ \\
\hline & p90 & 18.6 & $\geq \mathrm{p} 90$ & $1 / 38(3 \%)$ & $\geq p 90 \quad 0 / 17$ \\
\hline \multirow{2}{*}{$\begin{array}{l}\text { Glucose } \\
(\mathrm{mmol} / \mathrm{l})\end{array}$} & p75 & 4.4 & $\geq$ p75 & $23 / 38(61 \%)^{b}$ & $\geq$ p75 $3 / 17(18 \%)$ \\
\hline & p90 & 4.5 & $\geq \mathrm{p} 90$ & $19 / 38(50 \%)^{c}$ & $\geq p 90 \quad 2 / 17(12 \%)$ \\
\hline \multirow{2}{*}{$\begin{array}{l}\text { HDL cholesterol } \\
(\mathrm{mmol} / \mathrm{l})\end{array}$} & p25 & 0.9 & $\leq \mathrm{p} 25$ & $8 / 37(22 \%)$ & $\leq$ p $25 \quad 4 / 17(24 \%)$ \\
\hline & p10 & 0.7 & $\leq \mathrm{p} 10$ & 4/37 (11\%) & $\leq$ p10 $3 / 17(18 \%)$ \\
\hline \multirow{2}{*}{$\begin{array}{l}\text { Triglycerides } \\
(\mathrm{mmol} / \mathrm{l})\end{array}$} & p75 & 1.4 & $\geq$ p75 & $8 / 37(22 \%)$ & $\geq$ p75 $5 / 17(29 \%)$ \\
\hline & p90 & 1.5 & $\geq \mathrm{p} 90$ & 6/37 (16\%) & $\geq p 90 \quad 4 / 17(24 \%)$ \\
\hline
\end{tabular}

The second column shows 75 th and 90th percentile values (25th and 10th for HDL cholesterol) based on the term AGA children at 1 and $2 y$ of age. The next columns show for each metabolic syndrome component the number of term SGA and VLBW children with a value at or above this 75 th and 90th percentile value (for HDL cholesterol at or below the 25th and 10th percentile value); the number of children is followed by the total number of children in which the component is known and (between brackets) the percentage of children with a value at or above/below the percentile value.

For marked data, the observed percentage is significantly higher than expected based upon the distribution in term AGA children: atriglycerides $\geq p 75$ in 1-y old term SGA children $p=0.019$ (Chi-Square test). ${ }^{b}$ glucose $\geq p 75$ in 2-y old VLBW children $P=0.001$ (Chi-Square test). 'Glucose $\geq$ p90 in 2-y-old VLBW children $P<0.001$ (Chi-Square test).

There were no significant differences between VLBW and term AGA children and between term SGA and term AGA children.

\section{DISCUSSION}

The present study shows that 2-y-old VLBW infants have significantly higher glucose levels than term born AGA children. At $1 \mathrm{y}$ of age, term born SGA children have a high prevalence of high triglycerides compared to AGA children.

In our recent study, we showed that, when using cut-off values from the literature, 2-y-old VLBW infants have a high prevalence of raised blood pressure, high triglycerides, and low HDL cholesterol (11). In the present study, we could not confirm the high prevalence of high triglycerides and low HDL cholesterol in VLBW children. Fasting glucose levels of VLBW children were significantly higher than glucose levels of term AGA children. This is probably caused by reduced insulin sensitivity in VLBW children. In this small group, this hypothesis could not be confirmed with the HOMA values. Hofman et al. (4) showed that premature born children have reduced insulin sensitivity between 4 and $10 \mathrm{y}$ of age (measured with the use of Bergman's minimal model from paired insulin and glucose data during an intravenous glucose-tolerance test). Our results 
suggest that VLBW children already have reduced insulin sensitivity at 2 y corrected age; this has to be confirmed by measurement of insulin sensitivity, preferably by hyperinsulinemic euglycemic clamp technique, although this is hardly feasible at this age. In our earlier study, we did not find a high prevalence of high glucose levels (11).

The differences between the present study and our earlier study are caused by the findings that the cut-off value based on term born AGA children from our own population is higher for triglycerides, lower for HDL cholesterol and lower for glucose than the cut-off values used in our earlier study. In our opinion, the results of the present study are more reliable, as we now compare lipids and glucose of VLBW children with a control group of children of the same age and from the same population. The earlier used values were until now the best availabe cut-off values, but for lipids these cut-off values are based on studies in mainly older children from other parts of the world and performed more than 3 decades ago $(12,13)$ and for glucose this cut-off value is the same as used in adults (15). Therefore, these values are less appropriate to use as cut-off values for our VLBW children.

Previous studies show that school-aged SGA born children have reduced insulin sensitivity and higher blood pressure than AGA born controls $(2,3,6,8,9)$. Reduced insulin sensitivity in SGA born infants can already be demonstrated in early childhood $(5,7)$. In the present study, we showed that at $1 \mathrm{y}$ of age term born SGA children have a high prevalence of high triglycerides, with the cut-off value based on term born AGA children from the same population. The high prevalence of high triglycerides is probably caused by reduced insulin sensitivity, as insulin resistance in the liver results in very low-density lipoprotein overproduction and development of hypertriglyceridemia $(16,17)$. In this small group, this hypothesis could not be confirmed with the HOMA values. Our results are in accordance with those of Soto et al. (7); they found a tendency to higher triglyceride levels in 1-y-old SGA children compared to AGA children. High childhood triglycerides are an important predictor of adult cardiovascular disease (18). However, we did not find a significantly high prevalence of high triglycerides in 2 -y-old SGA children. This is in contradiction to the concept of tracking metabolic abnormalities from childhood to adulthood in this population at risk. Studies in larger groups of SGA children are needed to clarify this.

The results of our study have implications for the followup of term SGA children and VLBW children. As term SGA children as well as VLBW children have a higher prevalence of some metabolic syndrome components compared to term AGA children, parents should be counseled about the risk of cardiovascular disease and given life style advices.

The most important limitation of our study is the small number of children. The results have to be confirmed in larger groups of VLBW and SGA children. More accurate measurement of insulin sensitivity in these children, ideally using hyperinsulinemic euglycemic clamp technique although hardly feasible, could contribute to the understanding of the pathophysiology that leads to an adverse metabolic profile in VLBW and SGA children. Unfortunately, blood pressure measurements of term born children were not available, so comparison of blood pressure of VLBW children to term born children from our own population still has to be done.

In conclusion, in early childhood, both VLBW and term SGA children already have a high prevalence of some metabolic syndrome components compared to term AGA children. VLBW children have significantly higher glucose levels than term born AGA children at 2 y corrected age. SGA children have a high prevalence of high triglyceride levels at $1 \mathrm{y}$ of age. More studies are needed in larger groups of VLBW and SGA children, including more accurate measurement of insulin sensitivity and comparison of blood pressure to term AGA children.

\section{METHODS}

\section{Study Population}

The VLBW infants were part of the NIRTURE trial, an international multicenter randomized controlled trial investigating the role of early insulin therapy in VLBW infants (19). After written informed consent was obtained from both parents VLBW infants younger than $24 \mathrm{~h}$ of age and requiring intensive care were randomized to receive continuous intravenous infusion of insulin for the first $7 \mathrm{~d}$ of life or standard neonatal care with insulin treatment only in case of hyperglycemia. Exclusion criteria included maternal diabetes and major congenital anomalies. All infants participating in the NIRTURE trial in our neonatal intensive care unit were eligible for the present study.

The term infants were born from a low-risk population of pregnant women included in the first trimester in a prospective longitudinal study (Trophoblast study) which aimed to investigate the use of circulating trophoblast for prenatal diagnosis of pregnancy-associated diseases such as pre-eclampsia (20). The term born infants were divided in AGA and SGA; SGA was defined as a birth weight below the 10th percentile (21). Approval from the ethics committee of the VU University Medical Center was obtained.

\section{Data Collection}

At the (corrected) ages of $3 \mathrm{mo}, 1 \mathrm{y}$, and $2 \mathrm{y}$, anthropometry according to Dauncey et al. (22) was performed by a trained research nurse. Body weight was measured using an electronic scale to the nearest $0.1 \mathrm{~kg}$, standing height was measured to the nearest $0.1 \mathrm{~cm}$ and all lengths and circumferences were measured using a measuring tape to the nearest $0.1 \mathrm{~cm}$. BMI was calculated. Total body fat was calculated according to Dauncey from skinfold thickness measurements and body dimensions (22). SDS of weight, height, and BMI were calculated according to Dutch references $(23,24)$. In the VLBW infants, a blood sample was taken at 2 $\mathrm{y}$ corrected age and in the term born infants blood samples were taken at 1 and $2 \mathrm{y}$ of age, according to the specific study protocol. All blood samples were taken after a fasting period of at least $3 \mathrm{~h}$. Blood samples were used for measurement of total cholesterol, HDL cholesterol, triglycerides, glucose, and insulin. Insulin resistance was estimated by the $\mathrm{HOMA}=$ (fasting insulin $\mathrm{mU} / \mathrm{L} \times$ fasting glucose $\mathrm{mmol} / \mathrm{l}) / 22.5(25)$. Blood pressure was only measured in VLBW infants at $2 \mathrm{y}$ corrected age.

\section{Assays}

Total cholesterol, HDL cholesterol, and triglycerides were measured by enzymatic colorimetric assay (CHOD-PAP, HDL-C plus, and GPO-PAP respectively; Modular Analytics, Roche diagnostics, Mannheim, Germany). Interassay coefficient of variation is $1.9 \%$ at both 3.5 and $7.1 \mathrm{mmol} / \mathrm{l}$ for total cholesterol, $2.9 \%$ at $1.0 \mathrm{mmol} / \mathrm{l}$ and $2.8 \%$ at $2.4 \mathrm{mmol} / \mathrm{l}$ for HDL cholesterol and $3.0 \%$ at $1.1 \mathrm{mmol} / \mathrm{l}$ and $2.3 \%$ at $1.9 \mathrm{mmol} / \mathrm{l}$ for triglycerides. Glucose concentrations were measured by the hexokinase method (Modular Analytics, Roche diagnostics). Interassay coefficient of variation is $2.0 \%$ at $4.8 \mathrm{mmol} / \mathrm{l}$ and $1.8 \%$ at $19.8 \mathrm{mmol} / \mathrm{l}$. Insulin was measured by immunometric assay (Advia Centaur, Siemens Medical Solutions Diagnostics, Malvern, Pennsylvania). Lower limit of quantitation is $10 \mathrm{pmol} / \mathrm{l}$, intra-assay coefficient of variation is $4 \%$ at $20 \mathrm{pmol} / \mathrm{l}, 3 \%$ at $500 \mathrm{pmol} / \mathrm{l}$ and $4 \%$ at 
$1,500 \mathrm{pmol} / \mathrm{l}$ and interassay coefficient of variation is $8 \%$ at $24 \mathrm{pmol} / \mathrm{l}$ and $7 \%$ at both 780 and 3,000 pmol/l.

\section{Metabolic Syndrome Components}

According to the definition of Cook et al. (13), based on the criteria of the National Cholesterol Education Program (NCEP), Adult Treatment Panel III for the metabolic syndrome in adults (26), the metabolic syndrome is diagnosed in adolescents in the presence of at least three of the following five criteria: waist circumference $\geq 90$ th percentile; blood pressure (systolic and/or diastolic) $\geq 90$ th percentile; triglycerides $\geq 1.24 \mathrm{mmol} / \mathrm{l}(110 \mathrm{mg} / \mathrm{dl}) ; \mathrm{HDL}$ cholesterol $\leq 1.03$ $\mathrm{mmol} / \mathrm{l}$ ( $40 \mathrm{mg} / \mathrm{dl})$; fasting glucose $\geq 6.1 \mathrm{mmol} / \mathrm{l}(110 \mathrm{mg} / \mathrm{dl})(13)$. As the metabolic syndrome as an entity should not be diagnosed in children younger than $10 \mathrm{y}$ of age (15), we evaluated the components of the metabolic syndrome separately in the 1- and 2-y-old children in our study. Because waist circumference measurements were not part of the routine anthropometry, we used the definition of obesity of Weiss et al. (27): BMI SDS > 2 for age and sex.

In our recent study in 2-y-old VLBW infants (11), the cut-off values for blood pressure (systolic and/or diastolic $\geq 90$ th percentile for age, sex and height), triglycerides $(\geq 0.98 \mathrm{mmol} / \mathrm{l})$, HDL cholesterol $(\leq 1.03$ $\mathrm{mmol} / \mathrm{l})$, and glucose $(\geq 5.6 \mathrm{mmol} / \mathrm{l})$ were based on studies in other populations (12-15). The cut-off values for lipids were based on the NCEP Report of the Expert Panel on Blood Cholesterol Levels in Children and Adolescents; however, the percentile values in this report are based on studies that were performed more than $30 \mathrm{y}$ ago, included only a small number of children less than $4 \mathrm{y}$ old and made no distinction between term and preterm born children or AGA and SGA born children (12). The cut-off value for glucose was the same as the value used for adults, according to the International Diabetes Federation definition of the metabolic syndrome in children and adolescents (15). In the present study, we compare the values of the metabolic syndrome components in VLBW infants and term SGA infants with those of term AGA infants.

\section{Statistical Analysis}

Statistical analyses were performed using the Statistical Package of Social Sciences software for Microsoft Windows version 19 (SPSS, Chicago, IL). Differences between (sub)groups were evaluated using Student's $t$-test for normally distributed values, Mann-Whitney test for not normally distributed values and Chi-Square tests. Bivariate correlation analysis was performed to study the relation between components of the metabolic syndrome, birth weight, and parameters of body size and composition. Multiple regression analysis was used to determine which of these parameters were significant determinants of metabolic syndrome components at 1 and $2 \mathrm{y}$ of (corrected) age. For insulin levels below the limit of quantitation, a value of $1 \mathrm{pmol} / \mathrm{l}$ was used. $P$ values $<0.05$ were considered as significant.

\section{STATEMENT OF FINANCIAL SUPPORT}

No financial support was provided for this study.

Disclosure: The authors have no conflicts of interest to disclose.

\section{REFERENCES}

1. Barker DJ, Hales CN, Fall CH, Osmond C, Phipps K, Clark PM. Type 2 (noninsulin-dependent) diabetes mellitus, hypertension and hyperlipidaemia (syndrome X): relation to reduced fetal growth. Diabetologia 1993;36:62-7.

2. Arends NJ, Boonstra VH, Duivenvoorden HJ, Hofman PL, Cutfield WS, Hokken-Koelega AC. Reduced insulin sensitivity and the presence of cardiovascular risk factors in short prepubertal children born small for gestational age (SGA). Clin Endocrinol (Oxf) 2005;62:44-50.

3. Hofman PL, Cutfield WS, Robinson EM, et al. Insulin resistance in short children with intrauterine growth retardation. J Clin Endocrinol Metab 1997;82:402-6.

4. Hofman PL, Regan F, Jackson WE, et al. Premature birth and later insulin resistance. N Engl J Med 2004;351:2179-86.

5. Mericq V, Ong KK, Bazaes R, et al. Longitudinal changes in insulin sensitivity and secretion from birth to age three years in small- and appropriatefor-gestational-age children. Diabetologia 2005;48:2609-14.

6. Singhal A, Cole TJ, Fewtrell M, et al. Promotion of faster weight gain in infants born small for gestational age: is there an adverse effect on later blood pressure? Circulation 2007;115:213-20.
7. Soto N, Bazaes RA, Peña V, et al. Insulin sensitivity and secretion are related to catch-up growth in small-for-gestational-age infants at age 1 year: results from a prospective cohort. J Clin Endocrinol Metab 2003;88:3645-50.

8. Veening MA, Van Weissenbruch MM, Delemarre-Van De Waal HA. Glucose tolerance, insulin sensitivity, and insulin secretion in children born small for gestational age. J Clin Endocrinol Metab 2002;87:4657-61.

9. Veening MA, van Weissenbruch MM, Delemarre-van de Waal HA. Sequelae of syndrome $\mathrm{X}$ in children born small for gestational age. Horm Res 2004;61:103-7.

10. Jaddoe VW, de Jonge LL, Hofman A, Franco OH, Steegers EA, Gaillard R. First trimester fetal growth restriction and cardiovascular risk factors in school age children: population based cohort study. BMJ 2014;348:g14.

11. de Jong M, Lafeber HN, Cranendonk A, van Weissenbruch MM. Components of the metabolic syndrome in early childhood in very-lowbirth-weight infants. Horm Res Paediatr 2014;81:43-9.

12. American Academy of Pediatrics. National Cholesterol Education Program: Report of the Expert Panel on Blood Cholesterol Levels in Children and Adolescents. Pediatrics 1992;89:525-84.

13. Cook S, Weitzman M, Auinger P, Nguyen M, Dietz WH. Prevalence of a metabolic syndrome phenotype in adolescents: findings from the third National Health and Nutrition Examination Survey, 1988-1994. Arch Pediatr Adolesc Med 2003;157:821-7.

14. National High Blood Pressure Education Program Working Group on High Blood Pressure in Children and Adolescents. The fourth report on the diagnosis, evaluation, and treatment of high blood pressure in children and adolescents. Pediatrics 2004;114:555-76.

15. Zimmet P, Alberti KG, Kaufman F, et al.; IDF Consensus Group. The metabolic syndrome in children and adolescents - an IDF consensus report. Pediatr Diabetes 2007;8:299-306.

16. D’Adamo E, Santoro N, Caprio S. Metabolic syndrome in pediatrics: old concepts revised, new concepts discussed. Pediatr Clin North Am 2011;58:1241-55, xi.

17. Kamagate A, Dong HH. FoxO1 integrates insulin signaling to VLDL production. Cell Cycle 2008;7:3162-70.

18. Morrison JA, Glueck CJ, Wang P. Childhood risk factors predict cardiovascular disease, impaired fasting glucose plus type 2 diabetes mellitus, and high blood pressure 26 years later at a mean age of 38 years: the Princetonlipid research clinics follow-up study. Metabolism 2012;61:531-41.

19. Beardsall K, Vanhaesebrouck S, Ogilvy-Stuart AL, et al. Early insulin therapy in very-low-birth-weight infants. N Engl J Med 2008;359:1873-84.

20. Tjoa ML, van Vugt JM, Go AT, Blankenstein MA, Oudejans CB, van Wijk IJ. Elevated C-reactive protein levels during first trimester of pregnancy are indicative of preeclampsia and intrauterine growth restriction. J Reprod Immunol 2003;59:29-37.

21. Pollack RN, Divon MY. Intrauterine growth retardation: definition, classification, and etiology. Clin Obstet Gynecol 1992;35:99-107.

22. Dauncey MJ, Gandy G, Gairdner D. Assessment of total body fat in infancy from skinfold thickness measurements. Arch Dis Child 1977;52:223-7.

23. Fredriks AM, van Buuren S, Burgmeijer RJ, et al. Continuing positive secular growth change in The Netherlands 1955-1997. Pediatr Res 2000;47: $316-23$.

24. Fredriks AM, van Buuren S, Wit JM, Verloove-Vanhorick SP. Body index measurements in 1996-7 compared with 1980. Arch Dis Child 2000;82:107-12.

25. Matthews DR, Hosker JP, Rudenski AS, Naylor BA, Treacher DF, Turner RC. Homeostasis model assessment: insulin resistance and betacell function from fasting plasma glucose and insulin concentrations in man. Diabetologia 1985;28:412-9.

26. Executive Summary of The Third Report of The National Cholesterol Education Program (NCEP) Expert Panel on Detection, Evaluation, And Treatment of High Blood Cholesterol In Adults (Adult Treatment Panel III). JAMA 2001;285:2486-97.

27. Weiss R, Dziura J, Burgert TS, et al. Obesity and the metabolic syndrome in children and adolescents. N Engl J Med 2004;350:2362-74.

28. Niklasson A, Ericson A, Fryer JG, Karlberg J, Lawrence C, Karlberg P. An update of the Swedish reference standards for weight, length and head circumference at birth for given gestational age (1977-1981). Acta Paediatr Scand 1991;80:756-62. 